\title{
O LUGAR DE OCUPAÇÃO DO SUJEITO EM PEÇAS PUBLICITÁRIAS ${ }^{1}$
}

Arlete Ribeiro Nepomuceno*

Maria IEda Almeida Muniz**

\section{Resumo}

Partindo dos conceitos de enunciação postulados por Benveniste (1989), Ducrot (1987, 2002) e Guimarães (1989; 1995; 1996 e 2002), associados aos estudos de Dias (2002), entre outros; procuramos evidenciar os lugares de ocupação do sujeito e recortamos um exemplário de ocorrências extraídas de anúncios publicitários veiculados em fontes diversas. Por meio dos dados analisados, verificamos o caráter multifacetado que a língua pode apresentar, não fazendo sentido porfiar por uma formulação exata, estrita e restritiva de uma só possibilidade de análise, o que não caracteriza a abordagem como falha, ou imprecisa. Nessa direção, concluímos que o estudo da linguagem, do ponto de vista de uma sintaxe de bases enunciativas, contempla o uso relativo a tempo, espaço e sujeito da enunciação e a consideração de que enunciar é um ato singular de utilização da língua e como tal deve ser analisado.

PalaVRAS-CHAVE: Sujeito, enunciação, anúncio publicitário.

\section{CONSIDERAÇÕES INICIAIS}

Partindo de um estudo ancorado em bases enunciativas, propomo-nos a abordar espaços de ocupação do sujeito com um novo espectro de sintaxe, em que os lugares sintáticos não são concebidos como posições fixas, mas como espaços recortados na memória do dizer, o que contribui para que formas linguísticas ganhem pertinência nos processos sócio-históricos de constituição da língua.

\footnotetext{
* Universidade Estadual de Montes Claros (Unimontes). Montes Claros. Brasil. Bolsista da Fapemig. Mestre em Língua Portuguesa pela PUC-SP e doutoranda em Estudos Linguísticos na UFMG.

E-mail: arletenepo@gmail.com

** Universidade Tecnológica Federal do Paraná (UFTFP). Pato Branco. Brasil. Doutora em Linguística Aplicada pela PUC-SP/LAEL. Fapemig/Fundação Araucária.

E-mail:muniz@utfpr.edu.br
} 
Para tanto, elegemos como percurso teórico uma revisitação dos conceitos de enunciação postulados por Benveniste (1989), Ducrot (1987 e 2002) e Guimarães (1989; 1995; 1996 e 2002) - visando estabelecer um diálogo entre diferentes abordagens da enunciação, de maneira a ir criando uma tessitura dos estudos já existentes, destacando seus pontos divergentes, com vistas a apontar a pertinência para um estudo de bases enunciativas -, associados aos estudos de Dias (2002), entre outros autores.

Assim, para evidenciar os lugares de ocupação do sujeito, selecionamos vários exemplos dessa ocorrência extraídos de anúncios publicitários. De forma a realizar o seu objetivo, este trabalho será dividido em três partes. Primeiramente, há uma breve apresentação do quadro teórico relativo à enunciação, com ênfase no modelo proposto por Guimarães. Em seguida, explicitamos e analisamos os dados, finalizando com algumas considerações sobre as contribuições desse estudo.

\section{SituANDo A ENUNCIAÇão}

Ao longo dos anos, inúmeras foram as transformações pelas quais passaram os estudos da linguagem, mas talvez as mais salientes e mais significativas tenham sido provocadas pela enunciação, em virtude de ela ganhar matizes diferentes em consonância com a determinação atribuída a ela pelas diferentes perspectivas que a abordam; "mesmo porque abordá-la desprovida de determinações seria reduzi-la ao ato psicofisiológico de dizer algo" (LACERDA, 2009, p. 15). Em vista disso, a reflexão sobre a significação pôde não só ganhar novos contornos, como também formular novas questões e problematizar importantes campos das ciências humanas e da filosofia da linguagem.

Nessa direção, apresentamos um esboço de um quadro geral da teoria da enunciação com o intuito de confirmar a sua importância dentro dos estudos da sintaxe de bases enunciativas. Destacamos que, primeiramente, percorreremos os caminhos da teoria da enunciação preconizada por Benveniste (1989); depois por Ducrot (1987 e 2002); finalizando com Guimarães (1989; 1995; 1996 e 2002). ${ }^{1}$ Vale ressaltar que, embora citemos Benveniste e Ducrot, optamos por trabalhar a teoria da enunciação conforme Guimarães. 
Os estudos linguísticos de base saussuriana, os quais excluíram, por exemplo, entre outros, o sujeito e a história, até então restritos ao estudo da língua como depositária de virtualidades, têm o seu campo ampliado: a língua passa a ser usada. ${ }^{2}$ Há referência, e esta não é "qualquer uma porque o que diz eu é eu". ${ }^{3}$ Essa ampliação, reunindo discurso e as ligações da língua com o homem e a sociedade, culminou no que se passou a chamar Teoria da Enunciação, cujo pioneiro, Benveniste (1902-1976), em 1974, escreveu L'Appareil Formel de l'Énonciation.

Segundo Benveniste $(1989$, p. 82), "enunciação é este colocar em funcionamento a língua por um ato individual de utilização". Pelo estudo do ato, é esboçado, preliminarmente, o quadro da enunciação, em oposição ao que se denomina o quadro da língua. A partir do estudo do ato, passa-se a examinar a língua em funcionamento, ou seja, toda a língua submetida ao funcionamento. A respeito disso, eis a pertinência das observações do autor: [...] "Antes da enunciação, a língua não é senão possibilidade da língua. Depois da enunciação, a língua é efetuada em instância do discurso" (Benveniste, 1989, p. 83-84).

Entretanto, por essa via, a enunciação possibilita separar ao mesmo tempo o ato - objeto de estudo da Linguística da Enunciação - do produto, isto é, o enunciado. Esse ato, como assevera Flores e Teixeira (2008, p. 35), "é o próprio fato de o locutor relacionar com a língua a partir de determinadas formas linguísticas da enunciação que marcam essa relação". Sob essa ótica, enunciar é transformar individualmente a língua em discurso.

Nessa veia, não cabe mais falar em oposição língua/discurso, mas na relação constitutiva língua/discurso. A enunciação, nessa perspectiva, é ato de apropriação da língua pelo locutor, é a capacidade de o locutor se propor como sujeito de seu discurso, pondo-a em funcionamento, a partir do aparelho formal da enunciação. Assim, Benveniste trata a questão do sujeito da linguagem, para ele um sujeito da enunciação, como uma questão linguística: a enunciação é uma relação do sujeito com a língua. O sujeito dela se apropria, colocando-a em funcionamento.

Resguardando o caráter fundador dos estudos de Benveniste, os quais operam "nessa passagem da possibilidade da língua para uma instanciação discursiva dela" (DIAs, 2009), não podemos deixar de apontar um aspecto restrito de sua teoria: a adoção de uma subjetividade única. 
Nessa medida, eis que Guimarães denuncia:

Diria que esse aspecto faz parte dos problemas do tratamento enunciativo de Benveniste, ao qual se acresce para mim, como para outros linguistas e para a análise do discurso, a questão da centralidade deste sujeito da enunciação. Não se trata de um sujeito psicológico, não se trata de um sujeito pragmático, por exemplo, mas trata-se de um sujeito que tem a capacidade de apropriar-se da língua e semantizar, e fazer significar. (GUIMARÃEs, 1995, p. 47)

Em direção oposta a Benveniste (1989), Ducrot (1987), sempre atento ao surgimento de impasses que podem invalidar o eixo central da teoria desenvolvida por ele, diz que a argumentação está na língua, refuta a tese de que na base de cada enunciado emerge a ideia de um único autor e apresenta a teoria polifônica, afirmando que é possível verificar diferentes representações do sujeito da enunciação no sentido do enunciado.

Ressaltamos que, neste artigo, não fazemos um estudo da teoria de Ducrot em todos os seus desdobramentos, por exigir um espaço não pertinente para um trabalho introdutório com este. Na verdade, nossa principal intenção é evidenciar o que esse modo de tratar a argumentação apresenta para as questões semânticas e enunciativas como forma de justificar a sua inclusão na linguística da enunciação. Num pequeno esboço, faremos isso apresentando a teoria polifônica e a dos blocos semânticos.

Ducrot (1987) propõe que o sujeito se desdobra em diferentes vozes, inclusive naquilo que não está expresso no enunciado dito, porém está nele significado. Esse sujeito contemplado não é um produtor de fala, mas sim um produtor de sentidos no enunciado; dessa forma, a enunciação pode ser atribuída a um ou mais sujeitos.

Nesse contexto, a enunciação que era definida por Ducrot e Anscombre (1976, apud GuimarãEs, 1995, p. 56) como "a atividade de linguagem exercida por aquele que fala no momento em que fala vai se modificando e passa a ser definida como um acontecimento histórico do aparecimento do enunciado", ao se considerar que o sentido do enunciado é a representação que ele faz de sua enunciação, ou seja, do acontecimento de seu aparecimento. De acordo com Ducrot, a enunciação 
é o acontecimento constituído pelo aparecimento de um enunciado. A realização de um enunciado é de fato um acontecimento histórico: é dado existência a alguma coisa que não existia antes de se falar e que não existirá mais depois. É esta aparição momentânea que chamo "enunciação". (Ducrot, 1984, p. 168)

Apesar de esse posicionamento nos colocar no campo da multiplicidade das posições de sujeito, tomando, "de um certo modo, a polifonia como multiplicidade de consciências" (GUIMARÃES, 1995, p. 61), há a concepção de sentido em que a enunciação do enunciado esgota a representação de seu sentido. Isso ocorre em razão de a enunciação ser percebida aqui como acontecimento no qual não estão sendo levadas em consideração apenas as determinações de uma historicidade temporalista, já que esse acontecimento como histórico diz respeito somente a tempo, a cada momento tem-se um outro acontecimento.

Tal posicionamento, como veremos mais adiante, não coaduna com o pensamento de Guimarães, para "quem o sentido não é efeito da circunstância enunciativa, nem é só memória. O sentido são efeitos da memória e do presente do acontecimento: posições de sujeito, cruzamento de discursos no acontecimento" (GUIMARÃEs, 1995, p. 70). Nesse ponto, para o autor, um enunciado não é único, pois a cada vez que é proferido sofre injunções da memória do dizer e nele atualiza-se.

Por outro lado, numa época mais atual, Dias (2009), Ducrot e Carel, numa nova versão da teoria da argumentação, na qual se inclui a teoria dos blocos semânticos, rediscutem as situações de enunciação e a referência da forma como eram concebidas na década de 1980 e passam a postular que enunciar está na instância discursiva da língua, pois é do discurso que emerge o sentido. Sendo assim, torna-se oportuno citar a afirmação de Ducrot (2002, apud Dias, 2002): “o sentido de uma entidade linguística é, ou de evocar um conjunto de discursos, ou, se ela tem função puramente combinatória, de modificar os conjuntos de discursos associados a outras entidades".

A partir dessa nova empreitada, de acordo com Dias (2009), nesse deslocamento de Ducrot e Carel, o acontecimento enunciativo inclui uma evocação de discursos anteriores, ou seja, um já-enunciado, o qual se instala no acontecimento, constituindo, nas palavras de Dias, "a instância dos discursos evocados ou modificados na enunciação" (DiAs, 2009). 
Em linhas gerais, contra a concepção de unicidade do sujeito, pode-se dizer que a teoria de Ducrot é uma semântica argumentativa voltada às questões da enunciação, na medida em que considera, na representação do sentido do enunciado, tanto o fato de o sujeito se desdobrar numa perspectiva polifônica como a evocação de princípios argumentativos que dão a direção de como um dado enunciado deve ser interpretado numa situação $x$.

Nessa linha de ideias, é lícito ressaltar que Benveniste (1989), como também Ducrot (1987), não trabalham com o modo por meio do qual a dimensão social do dizer penetra na constituição desse sujeito. Assim é que, no Brasil, outro expoente da linguística da enunciação, Guimarães, para quem enunciar é colocar a língua em funcionamento gerenciada por uma memória de dizeres sociais que a faz significar, advoga um novo olhar sobre a figura do sujeito entrelaçado no lugar social do dizer, em que esse sujeito é afetado pelos lugares sociais nos quais ele se apresenta com papéis enunciativos.

Como bem afirma Guimarães (1989, p. 78), “a enunciação é um acontecimento sócio-histórico da produção do enunciado". Assim, postula que é a história que determinará o sentido, porém ela não pode ser entendida como uma pontualidade marcada no tempo cronológico. ${ }^{4}$ Em outras palavras, segundo o autor, é preciso

tratar a questão do sentido como uma questão enunciativa em que a enunciação seja vista historicamente. Este espaço procura se apresentar a partir da consideração de que a significação é histórica, mas não no sentido temporal, historiográfico, mas no sentido de que a significação será determinada pelas condições sociais de sua existência. Sua materialidade é esta historicidade [...] o sentido deve ser tratado como discursivo e definido a partir do acontecimento enunciativo. (GUIMARÃES, 1995, p. 66)

Sob essa perspectiva, o sentido é visto na cenografia enunciativa e constitui-se social e historicamente a partir de um acontecimento do dizer, sendo, portanto, lícito afirmar que os sentidos de um enunciado são os efeitos de suas enunciações. Outrossim, a produção de sentidos numa enunciação não acontece de uma única maneira, tampouco ocorre pela repetição de significados prontos e preexistentes. A cada nova 
enunciação, sentidos são construídos e (re) construídos e, até mesmo, esquecidos de modo a proporcionarem um cruzamento de dizeres em meio à criação de dizeres novos. Nesse viés, nas palavras de Guimarães:

não seria possível a existência de um enunciado único. Faz parte das condições de existência de um enunciado que existam outros. Assim seu caráter é necessariamente relacional. Só há um enunciado se houver mais de um. Ou seja, é impossível pensar a linguagem, o sentido fora de uma relação. Nada se mostra a si mesmo na linguagem. Algo sozinho nunca é linguagem. Algo só é linguagem com outros elementos e nas suas relações com o sujeito. Isto se dá o caráter inescapavelmente histórico da linguagem. (GuIMARÃES, 1989, p. 74)

Assim, um enunciado não é único, a cada vez que é produzido sofre intervenções da memória de sentidos que o afeta, constituindo-se de já-ditos, resgatados no acontecimento da enunciação. Considerando o interdiscurso como a memória do dizer, como o enunciável (o dizível), podemos assumir a posição de que o sentido num acontecimento são efeitos da presença do interdiscurso. Ou melhor, são efeitos de cruzamento de discursos diferentes no acontecimento. Eis aqui a pertinência das palavras de Guimarães:

Pode-se dizer, então, que as formas são o que são pela história de suas enunciações. Uma forma é na língua o que ela se tornou pela história de seus funcionamentos na enunciação. Deste modo, devese considerar que a língua tem em si a memória desta história, ou seja, a língua carrega na sua estrutura as marcas de seu passado. O que uma forma é, em um certo momento, tem a marca de como ela funcionou nas enunciações em que a língua pôs a funcionar. (Guimarães, 1996, p. 27)

Dessa forma, na visão do autor, a língua está sujeita a uma memória do dizível; a memória não é autônoma, é preciso, por exemplo, verificar as diferenças sociais, pois a sociedade é recortada socialmente, e os eixos pelos quais se recortam são múltiplos. A memória nasce da heterogeneidade e é recortada por ela. Assim, "a enunciação é o lugar de funcionamento da própria língua movimentada pelo interdiscurso, pela memória do dizer". Uma forma na língua não é, por exemplo, um 
somatório de passados, mas sim de acontecimentos enunciativos nos quais o presente e o interdiscurso é que fazem a língua. Uma vez mais, a enunciação é um acontecimento de linguagem que se dá como espaço de memória de acontecimento, o qual ocorre porque a língua funciona ao ser afetada pelo interdiscurso. Portanto, quando o indivíduo se encontra interpelado como sujeito e se vê como identidade, a língua se pôs em funcionamento.

Cumpre salientar, aqui, segundo Guimarães (2002, p. 15), o fato de que memória pressupõe memória de sentidos (memória discursiva: interdiscurso, visto que se trata de um elemento que está a serviço do discurso - cujo conceito, concebido por Pêcheux, advém da Análise do discurso). Ela se estrutura pelo esquecimento de que já significa. Ser sujeito de seu dizer, ser sujeito é falar de uma posição de sujeito. Essa memória difere do passado no acontecimento, que é memorável de enunciações recortadas pela temporalização do acontecimento.

Guimarães (2002, p. 11-14), ancorado no postulado de que a enunciação não se acaba em um acontecimento limitado e pontual, advoga que a enunciação é um acontecimento em que se instala sua própria temporalidade: "ele está num presente de um antes e um depois no tempo" (Guimarães, 2002, p. 11). Nessa direção, há no acontecimento uma convergência do passado e uma projeção do futuro, os quais se concretizam no presente da enunciação.

O passado não figura como uma lembrança, uma recordação pessoal de fatos anteriores, não é um antes, mas um memorável recortado pelo próprio acontecimento, o qual tem também o futuro como uma latência de futuro. Em outros termos, essa "latência de futuro, que, no acontecimento, projeta sentido, significa porque o acontecimento recorta um passado memorável" (GuIMARÃES, 2002, p. 12). Por outro lado, o futuro no acontecimento "tem como seu um depois incontornável e próprio do dizer. Todo acontecimento de linguagem significa porque projeta em si mesmo um futuro" (GUIMARÃEs, 2002, p. 12).

A partir desses fatos, conforme atesta o autor, o acontecimento constitui um espaço de temporalização. Tal ocorrência evidencia, por conseguinte, que, a cada acontecimento enunciativo, há não só uma nova temporalização, como também um novo espaço de conviviabilidade de tempo, sem a qual não é possível a enunciação. 
Assim é que, ancorados nas considerações de Guimarães (2002, p. 23), corroborando a sua ideia de que "assumir a palavra é pôr-se no lugar que enuncia", procuraremos analisar o papel do sujeito como participante da enunciação.

\section{OCUPaÇÃo do GN SUJeito SOB UM OlHAR ENUNCIATIVO}

Antes de efetuarmos a análise das ocorrências do papel de ocupação do sujeito, num primeiro momento, é lícito explicar a tipificação de sujeito com a qual vamos trabalhar. Num segundo momento, explicitaremos a força da anterioridade. Em seguida, vamos nos centrar na análise dos anúncios publicitários.

Sem muitos detalhes, ou melhor, sem um rigor devido, segundo Dias (2002, apud Pereira, 2008, p. 88), a atualização do lugar de sujeito pode ser realizada de quatro formas: sujeito base, suporte, projeção e perfil. Ressaltamos que, tendo em vista a especificidade do nosso corpus, o qual apresenta sujeitos suporte/perfil, não faremos menção aos demais tipos de sujeito.

O sujeito suporte apresenta o lugar de sujeito ocupado por um dêitico, o qual funciona como um suporte de ancoragem na enunciação, sendo dependente da especificidade temporal instalada no momento presente em que a sentença foi proferida. Por vezes, o lugar do sujeito pode não ser ocupado por um dêitico e haver uma categoria vazia que se instala e funciona como suporte para a ancoragem do lugar de sujeito na enunciação (por exemplo, um morfema número-pessoal ou um modo verbal qualquer). Essa consideração pode ser muito bem demonstrada por Dias (2002, apud Pereira, 2008, p. 90), com este excerto:

Quando o lugar do sujeito não é lexicalmente materializado, a identificação das perspectivas de primeira e de segunda pessoa é possível, seja através das desinências verbais $[\ldots],{ }^{5}$ seja através do caráter imperativo da sentença $[. ..]{ }^{6}$ seja através da presença do vocativo (28), ou mesmo através da entonação - marcada pela exclamação na escrita $-(29){ }^{7}$

Vale assinalar que esse tipo de sujeito pode não se ancorar propriamente nas instâncias do dizer que compõem o aparelho formal da 
enunciação, mas se ancorar na temática do texto, ou seja, na textualidade. $^{8}$

Além disso, esse tipo de sujeito não pode receber determinações, entre as quais destacamos artigos definidos e indefinidos, pois possui como "suportes" dêiticos: eu, você, nós, aquilo, isso etc. que apontam para figuras enunciativas. No caso desse tipo de sujeito, o verbo é acionado "quando a ancoragem alcança a especificidade de base constituída externamente ao corpo da sentença” (DiAs, 2002 apud Pereira, 2008), tendo a ancoragem do dêitico em alguma base, seja na figura enunciativa, seja na construção temática. Contudo, como veremos mais adiante na análise do corpus, a constituição dessa base pode ser diferente, dependente dos modos de representação do sujeito na enunciação. Nessa direção, Guimarães (1989) postula que você nem sempre funciona como você. Em outros termos: pronomes pessoais como você, ou mesmo nós, eu e a expressão a gente podem aparecer de modo desordenado, não se referindo com exatidão ao locutor ou ao alocutário, mas a uma dimensão mais geral na qual se inscreve todo aquele que. Para Pereira (2008, p. 94), é preferível "conceber este tipo de ocorrência como a montagem de uma encenação, na qual o sujeito, ao mesmo tempo em que se distancia do que diz, insere-se nas possibilidades admitidas pelo seu dizer".

O sujeito perfil, por sua vez, é sempre caracterizado por quem, aquele que, todo aquele que, recebendo a marca de uma enunciação generalizadora, do qual falaremos com detalhes mais adiante quando analisarmos o corpus.

Assim é que, na contramão da gramática tradicional, partiremos da concepção de que a projeção do lugar do sujeito é da ordem enunciativa, não dependendo, pois, de uma projeção do verbo. Tal concepção encontra-se fundada na anterioridade de predicação.

Segundo Pereira (2008, p. 100), o lugar de sujeito possui uma força de anterioridade. Tal fato leva-nos a buscar a anterioridade na textualidade ou na enunciação, o que justifica mencionarmos a presença de uma flexão verbal. Pensando assim, a anterioridade se constitui como o ponto de partida para o acionamento do verbo, sendo o sujeito atualizado de diversas formas, as quais são capazes de retirar o verbo do seu estado de infinitude. 
Os tipos de sujeito apontados se constituem como uma forma de perceber essa anterioridade que nem sempre possuem o seu campo demarcado por elementos linguísticos, nem sempre possuem ancoragem no texto, nem sempre possuem uma constituição referencial delimitada. Esse fato está relacionado à enunciação. Nesse contexto, na configuração dos lugares sintáticos de projeção do lugar de sujeito subjaz a concepção de uma sintaxe de bases enunciativas embasada numa articulação sintática atrelada à enunciação, que passa por recortes de memória específicos de cada enunciado.

Para fins de análise, vejamos alguns papéis de ocupação do sujeito que podem ser codificados no nosso exemplário de anúncios publicitários:

(1) Parece mágica, mas é Sedex. Mandou. Chegou.

(2) Promoção O Boticário na garagem. Raspou, Achou, Ganhou!

(3) Casas Bahia. Clicou. Economizou.

(4) Posto Boa Viagem. Abasteceu. Lavou.

(5) Pronta Entrega D \& D. Gostou. Olhou. Levou.

(6) Rádio FM. Ligou. Participou. Ganhou.

(7) Gilette Prestobarba Excel. Leve 4. Pague 3.

(8) Bretas. Tá no Bretas. Tá em casa.

(9) Gostou? Alugue na Master.

(10) Tang. Preparou. Bebeu. Faz.

Os anúncios publicitários de (1) a (10) são ilustrativos da ocupação do lugar de sujeito por grupo nominal (doravante GN) encabeçado pelo pronome Quem ou pelas expressões pronominais indefinidas Aquele que, Todo aquele que, os quais figuram um amplo escopo de referência em razão de designarem qualquer um que se enquadre no perfil apresentado no predicado.

Assim é que esse sujeito perfil é marcado pela enunciação generalizadora na ancoragem do lugar de sujeito, em que todo aquele que "se adequar a este perfil estará se ajustando a uma verdade condensada nos próprios domínios do corpo textual no qual se insere a sentença" (Dias, 2002 apud PereirA, 2008, p. 99). A constituição da 
generalidade seria não mais que uma possibilidade da língua marcada na ocupação do lugar de sujeito relacionada a um domínio de sentidos que se investe no predicado.

O fato de o sujeito não ocupar explicitamente o seu papel parece advir das condições discursivas que ancoram a constituição desse acontecimento enunciativo, figurando, por exemplo, como estratégias discursivas criativas utilizadas pelo locutor para organizar funcionalmente seu texto, sobre as quais não falaremos por fugir, aqui, da nossa proposta de trabalho.

Vale assinalar, no entanto, que, apesar desse amplo espectro de referência do sujeito, esses elementos quem, aquele que e todo aquele que possuem a ocupação limitada apenas ao lugar de sujeito. Por outro lado, ocupando também o lugar de sujeito (exemplos (1) a (6)), se, em vez de quem, aquele que, todo aquele que, projetarmos a ancoragem do lugar de sujeito como campo de referência um nome, como, por exemplo, (Maria mandou. Chegou; João raspou. Achou. Ganhou; Casas Bahia. Pedro clicou. Economizou, entre outros), teremos como outra ancoragem do lugar do sujeito um referente pontual, um modo de enunciação mais especificador, constituindo um caráter não genérico na ancoragem desse lugar, formado por pessoalidade, e evidenciando uma nova situação enunciativa.

Tal pessoalidade não implica dizer que, nos exemplos com pronomes e expressões indefinidas, não haja pessoalidade. No modo de enunciação da sentença, temos diferentes molduras referenciais, as quais constituem modos linguísticos que conservam, em sua constituição, memórias de sentidos vinculadas a domínios de inteligibidade diferentes, que nos permitem sair de um modo de enunciação mais genérico para outro mais específico.

Podemos ter, ainda, casos de sujeito suporte. Diferentemente do sujeito perfil, que possui a determinação de quem, aquele que, todo aquele que, o sujeito suporte está relacionado a dêiticos como eu, você, nós, apontando para figuras enunciativas, para GN ou para porções de texto. Esse tipo de sujeito, de acordo com Dias (2002, apud Pereira, 2008, p. 89), "é formado por um dêitico, o qual funciona como uma âncora, que se aporta, seja na pessoa constituída como perspectiva de enunciação, seja num campo de orientação temática (texto)". Logo, no sujeito suporte, o verbo é posto em funcionamento "quando a ancoragem 
alcança a especificidade da base constituída externamente ao corpo da sentença" (Dias, 2002 apud Pereira, 2008, p. 93), como nos exemplos que se seguem:

(3) Casa Bahia. (Você) clicou. (Você) economizou.

(4) Posto Boa Viagem. (Você) Abasteceu. (Você) Lavou.

(6) Rádio FM. (Você) ligou. (Você) participou. (Você) ganhou.

(10) Tang. (Você) preparou. (Você) bebeu. (Você) faz.

Nos exemplos (3), (4), (6) e (10), o dêitico de ancoragem que funciona como suporte na enunciação é você, cuja constituição da base é difusa, pois não está ancorado especificamente no alocutário, pessoa discursiva do aparelho formal da enunciação. Você está relacionado com uma dimensão mais geral em que se inscreve todo aquele que se dispuser a clicar, abastecer, ligar e preparar, por exemplo.

Com efeito, nesses casos arrolados, você não se refere pontualmente ao alocutário, mas sim a uma dimensão mais genérica em que se insere inclusive o locutor, que se apresenta de modo desordenado. Tal fato comprova que, para o preenchimento dos espaços dos dêiticos no sujeito suporte, não nos é possível circunscrever limites, esmiuçar precisamente e muito menos materialmente a ocupação. $\mathrm{Na}$ cena enunciativa, segundo Guimarães (2002, p. 23), "'aquele que fala' ou 'aquele para quem se fala' não são pessoas, mas uma configuração do agenciamento enunciativo".

Dessa forma, a cena enunciativa é constituída de lugares de dizer temporalizados e especificados no acontecimento. Vista sob esse prisma, a língua funciona no/pelo acontecimento enunciativo, e não pela assunção de um indivíduo. Contudo, cabe-nos fazer uma ressalva: ainda que possamos reconhecer a possibilidade de os exemplos de (1) a (10) se encaixarem no tipo suporte, validamos a proposta de sujeito perfil, tendo em vista que acreditamos que o objetivo maior do locutor é demonstrar que os produtos anunciados estão ao alcance de todos.

Como bem afirma Guimarães (2002, p. 25): "um outro lugar de dizer, que se apresenta como o apagamento do lugar social, é o do enunciador-genérico". 9 Ao fazer menção ao enunciador-genérico, ele enquadra nesses casos o que consideramos como sujeito perfil, demonstrando, assim, que, em tais situações, "o que se diz não é de um 
lugar individual, independente de qualquer contexto, mas como aquilo que todos dizem" (GuiMARÃEs, 2002, p. 25).

Nas palavras de Guimarães (2002, p. 18), a constituição da cena enunciativa ocorre em espaços de funcionamento da língua, "habitados por falantes, ${ }^{10}$ que se dividem, redividem, se misturam, desfazem, transformam por uma disputa incessante”. Esses espaços, constituídos pela equivocidade do acontecimento, proporcionam aos falantes não só se identificarem, como também se dividirem hierarquicamente em consonância com os dizeres utilizados por eles nas enunciações das quais fazem parte. Tal aspecto fornece aos usuários da língua a garantia de "poder dizer certas coisas e não outras, a poder falar de certos lugares e não de outros, a ter certos interlocutores e não outros" (GUIMARÃES, 2002, p. 21).

Ainda segundo o autor, a enunciação é um acontecimento em que se instala uma temporalidade própria. Assim, o presente da enunciação possui duas projeções - um passado e um futuro -: uma memória histórico-social entrecortada por enunciações anteriores releva-se na constituição dos sentidos representados no presente do acontecimento. Essa representação produz uma futuridade que constituirá, sob o signo da regularidade, o corpo memorável de outras enunciações. A partir dessas constatações, no caso desses anúncios publicitários, ao dizermos, por exemplo:

Parece mágica, mas é Sedex. Se mandou, chegou;

Parece mágica, mas é Sedex. Quando manda, chega;

Parece mágica, mas é Sedex. Porque manda, chega, entre outros, observamos sentidos outros que emergem na materialidade linguística de sedex, mandar, chegar. Esses elementos linguísticos - sedex, mandar, chegar -, que constituem a referência, combinam-se no enunciado e produzem condições de enfoque na memória de sentidos que perpassam a materialidade linguística desses elementos.

Assim é que, por exemplo, no enunciado Parece mágica, mas é Sedex. Mandou. Chegou., temos como focalização o fato de parecer mágico, mas o Sedex é um meio eficiente e rápido de entregas de produtos, levando o alocutário a utilizá-lo, imprimindo a confiabilidade dos serviços oferecidos pelos Correios. Como os sentidos se apresentam 
entrecortados, outros sentidos podem ser perfeitamente constituídos. Desse modo, percebemos que, em Parece mágica, mas é Sedex, há a presença latente de um virtual que pode se atualizar perfeitamente em uma ideia de condição, tempo, causa, entre outros, dependendo do acontecimento enunciativo.

Nessa veia, tomando como ponto de partida a articulação dos elementos no enunciado, temos o que Guimarães (2002, p. 12) chamou de futuridade, sem a qual não há projeção, não há interpretável. Também Lacerda afirma que "os sentidos mudam, e a referência muda justamente porque a atualidade do acontecimento é capaz de agregar novas perspectivas aos recortes de memória, projetando diferenças para os acontecimentos futuros" (LACERDA, 2009, p. 28).

À luz desse quadro, é fato que a enunciação não se esgota em um acontecimento delimitado, datado por hora, minuto, segundo. A referência é estabelecida em relação à enunciação; formada, construída entre a atualidade do dizer, na qual são estabelecidos e representados os enunciadores, e o domínio histórico, resgatado pelos recortes realizados na rede interdiscursiva por um locutor a partir de seu lugar sócio-histórico.

Por meio desses exemplos, percebendo a representação das possibilidades de análise que se abrem a partir da consideração à enunciação, podemos dizer, ainda, que vimos o caráter multifacetado que a língua pode apresentar, não fazendo sentido insistir numa formulação exata, estrita e restritiva de uma só possibilidade de análise. Há de se destacar que a abertura dessas possibilidades não caracteriza a análise dos dados como falha, tampouco como imprecisa, inválida. $\mathrm{Na}$ verdade, o que se sabe é que elas são situações de enunciação, um modo de dizer em atividade na língua. Portanto, os dizeres - os arranjos sintáticos - se (re) constroem no acontecimento.

\section{CONCLUSÃo}

Como podemos constatar ao longo desta análise, o estudo da linguagem, do ponto de vista de uma sintaxe de bases enunciativas, contempla o uso relativo a tempo, espaço e sujeito da enunciação e a 
consideração de que enunciar é um ato singular de utilização da língua que se constitui na memória do dizer e como tal deve ser analisado.

Diante disso, tal estudo poderá contribuir para mudar o espectro dos estudos sintáticos, uma vez que a sintaxe não se reduz à sua forma, mas que "as formas da língua são o que são pela história. Uma forma é na língua o que ela se tornou pela história de seus funcionamentos na enunciação" (GUIMARÃES, 1996, p. 27).

$\mathrm{Na}$ verdade, a sintaxe está enraizada, entrecortada no/pelo acontecimento, fazendo com que a constituição das categorias linguísticas sofra injunções do domínio discursivo da referência, não podendo ser concebida como uma posição engessada, fixa, mas sim como um lugar sintático, espaço de recortes na memória.

THE OCCUPATION PLACE OF THE SUBJECT IN ADVERTISING

\section{AbStRact}

According to a study based on enunciation, we propose to address areas of occupation of the subject with a new spectrum of syntax. To this end, we chose to revisit a theoretical approach of enunciation of the concepts postulated by Benveniste (1989), Ducrot (1987 e 2002), Guimarães (1989; 1995; 1996 e 2002), along with the studies of Dias (2002). In this context in an attempt to show the places of occupation of the subject, we used a set of examples taken from commercials from various sources. It was possible to perceive the representation of possible analyses when considering the utterance and thus see the appearance of the multifaceted character of language. There was no attempt to create sense as an exact formulation, a strict and restrictive one and only possibility for analysis. The breadth of these possibilities does not characterize the data analysis as a failure, nor as inaccurate nor invalid. In this sense we conclude that the study of language in terms of an enunciative syntax contemplates the relativity of use based on time, place and the subject of the enunciation and the consideration that to enunciate is a singular act of the use of the language that is constituted in the memory of speech and as such should be analyzed.

KEY WORDS: Subject, enunciation, advertisement. 


\section{Notas}

1 Este artigo é fruto de uma comunicação oral apresentada no $58^{\circ}$ GEL UFScar em julho de 2010.

$2 \mathrm{O}$ critério de escolha desses autores deve-se à representatividade de seus trabalhos, na época de sua produção, como expressão do paradigma vigente ou como ruptura em relação ao modelo de se produzir conhecimento linguístico em vigor naquele momento. Dessa forma, com base em Kuhn (2000), esses autores traduzem a continuidade ou a descontinuidade nas reflexões sobre a linguagem, por expressarem uma fase de ciência normal ou um período de crise em que novas ideias estão em construção.

3 Ressaltamos o fato de que, de acordo com Flores et al. (2008, p. 76), apesar de Benveniste considerar a noção de língua dada por Saussure, "não significa que Benveniste simplesmente dê prosseguimento à proposta saussuriana apresentando a linguística da fala".

4 Nas palavras de Flores et al. (2008, p. 51), ao postular eu (referente) diz $e u$ (referido), com a noção de referência, aflora a noção de sujeito. Nesse caminho, "a língua passa a 'funcionar' pelo ato individual de utilização da própria língua, pois eu é signo que é usado para atribuir referência àquele que como eu se propõe".

5 De acordo com Guimarães (1995, p. 66), muitos estudiosos da linguagem têm se preocupado com a história. A análise do discurso se constitui a partir da inclusão dessa preocupação.

6 A frase "E fizemos uma casa na parte mais alta do terreno" exemplifica a afirmação feita.

7 Ex.: "L2 não é umidade... umidade é um troço que permanece... agora... frio... entra num frigorífico... L1 [não... sinto uma umidade... L2 entra dentro de um frigorífico que você vai ver que é diferente..." [n.276, entr. cnc]

8 Ex.: (28) Roubando a viola de Pedro, hein Paulo; (29) "Roubando a viola de Pedro!" (Dias, 2002, p. 56).

9 Por razões de espaço, não explicaremos esmiuçadamente a ancoragem na textualidade. Para maiores detalhes, consulte Dias (2002), Conte (2003) e Pereira (2008).

10 Segundo Guimarães (2002, p. 18), falantes são sujeitos divididos por seus direitos ao dizer e aos modos de dizer. 


\section{REFERÊNCIAS}

Benveniste, E. O aparelho formal da enunciação. Problemas de linguística geral II. São Paulo: Pontes, 1989.

Conte, M. E. Encapsulamento anafórico. In: Cavalcanti, M. M.; Rodrigues, B. B.; Ciulla, A. (Org.). Referenciação. São Paulo: Contexto, 2003.

DiAs, L. F. Fundamentos do sujeito gramatical: uma perspectiva da enunciação. In: Zandwais, A. (Org.). Ensaios: relações entre pragmática e enunciação. Porto Alegre: Sagra Luzzato, 2002.

DiAs, L. F. Enunciação e regularidade sintática. In: Cadernos de estudos linguísticos. n. 50, v. 2, Campinas, 2009. (No prelo).

Ducrot, O. Esboço de uma teoria polifônica da enunciação. $O$ dizer e o dito. Campinas: Pontes, 1987.

Flores, V. N. et al. Enunciação e gramática. São Paulo: Contexto. 2008.

Guimarães, E. Enunciação e história. In: Guimarães, E. (Org.). História e sentido na linguagem. Campinas: Pontes. Cortez, 1989.

Guimarães E. Historicidade do sentido. Os limites do sentido: um estudo histórico e enunciativo da linguagem. Campinas: Pontes, 1995.

Guimarães, E. Enunciação, língua, memória. Revista da Anpoll, n. 2, 1996.

Guimarães, E. Semântica do acontecimento: um estudo enunciativo da designação. Campinas: Pontes, 2002.

KuHn, T. A estrutura das revoluções cientificas. 5. ed. São Paulo: Perspectiva, 2000 .

Lacerda, P. B. G. Sentenças proverbiais: um estudo sintático-semântico de bases enunciativas. Dissertação (Mestrado) - Universidade Federal de Minas Gerais, Belo Horizonte, 2009.

Pereira, B. K. A convergência de sujeito e objeto direto: por uma sintaxe de bases enunciativas. Dissertação (Mestrado) - Universidade Federal de Minas Gerais, Belo Horizonte, 2008. 